\title{
Hyperoxia affects the regional pulmonary ventilation/perfusion ratio: an electrical impedance tomography study
}

Y. Li, Erik Tesselaar, J.B. Borges, S.H. Bohm, Folke Sjöberg and B. Janerot-Sjoberg

\section{Linköping University Post Print}

\section{Tweet}

N.B.: When citing this work, cite the original article.

Original Publication:

Y. Li, Erik Tesselaar, J.B. Borges, S.H. Bohm, Folke Sjöberg and B. Janerot-Sjoberg, Hyperoxia affects the regional pulmonary ventilation/perfusion ratio: an electrical impedance tomography study, 2014, Acta Anaesthesiologica Scandinavica, (58), 6, 716-725.

http://dx.doi.org/10.1111/aas.12323

Copyright: Wiley

http://eu.wiley.com/WileyCDA/

Postprint available at: Linköping University Electronic Press

http://urn.kb.se/resolve?urn=urn:nbn:se:liu:diva-109168 


\title{
Hyperoxia affects the regional pulmonary ventilation/perfusion ratio: an electrical impedance tomography study.
}

\author{
Yuhong Li ${ }^{1,2}$ (yuh_li@hotmail.com) \\ Erik Tesselaar² (erik.tesselaar@liu.se) \\ João Batista Borges ${ }^{3,4}$ (joao.batista_borges@ surgsci.uu.se) \\ Stephan H Böhm ${ }^{5}$ (shb@ swisstom.com) ${ }^{1}$ \\ Folke Sjöberg ${ }^{2,6}$ (folke.sjoberg@liu.se) \\ Birgitta Janerot-Sjöberg ${ }^{7,8}$ (birgitta.janerot@ki.se)
}

${ }^{1}$ Department of Anesthesiology, Shaoxing People’s Hospital of Zhejiang University, People’s Republic of China

${ }^{2}$ Department of Clinical and Experimental Medicine, Linköping University, Sweden

${ }^{3}$ Hedenstierna Laboratory, Department of Surgical Sciences, Section of Anesthesiology \& Critical Care, Uppsala University, Sweden.

${ }^{4}$ Laboratório de Pneumologia LIM-09, Disciplina de Pneumologia, Heart Institute (Incor), Hospital das Clínicas da Faculdade de Medicina da Universidade de São Paulo, Brazil.

${ }^{5}$ Swisstom AG, Schulstrasse 1, Landquart, Switzerland

${ }^{6}$ Department of Hand and Plastic Surgery, Linköping University Hospital, Sweden

${ }^{7}$ Department of Clinical Science, Intervention and Technology, Karolinska Institutet, Stockholm, Sweden

${ }^{8}$ Department of Clinical Physiology, Karolinska University Hospital, Stockholm, Sweden

Address for Correspondence:

Birgitta Janerot Sjöberg, Professor and Senior Consultant

Karolinska Institutet, CLINTEC, Alfred Nobels Allé 10 (3), 14186 Huddinge, Stockholm

Tel: +46 (0)70 5093397

E-mail: birgitta.janerot@ki.se

Running Head: Hyperoxic pulmonary V/Q mismatch

\footnotetext{
${ }^{1}$ Competing interests: SHB is co-founder of Swisstom AG and its Medical Director. He filed several patents on EIT. Otherwise the authors declare that they have no conflicting interests.
} 


\begin{abstract}
Background

The way in which hyperoxia affects pulmonary ventilation and perfusion is not fully understood. We investigated how an increase in oxygen partial pressure in healthy young volunteers affects pulmonary ventilation and perfusion measured by thoracic electrical impedance tomography (EIT).
\end{abstract}

\title{
Methods
}

Twelve semi-supine healthy male volunteers aged 21-36 years were studied while breathing room air and air-oxygen mixtures $\left(\mathrm{F}_{\mathrm{i}} \mathrm{O}_{2}\right)$ that resulted in predetermined transcutaneous oxygen partial pressures $\left(\mathrm{tcPO} \mathrm{P}_{2}\right)$ of 20,40 and $60 \mathrm{kPa}$. The magnitude of ventilation $\left(\Delta \mathrm{Z}_{\mathrm{v}}\right)$ - and perfusion $\left(\Delta \mathrm{Z}_{\mathrm{Q}}\right)$-related changes in cyclic impedance variations, were determined using an EIT-prototype equipped with 32 electrodes around the thorax. Regional changes in ventral and dorsal right lung ventilation (V) and perfusion (Q) were estimated and V/Q-ratios calculated.

\section{Results}

There were no significant changes in $\Delta \mathrm{Z}_{\mathrm{v}}$ with increasing $\mathrm{tcPO}_{2}$ levels. $\Delta \mathrm{Z}_{\mathrm{Q}}$ in the dorsal lung increased with increasing $\mathrm{tcPO}_{2}(p=0.01)$ whereas no such change was seen in the ventral lung. There was a simultaneous decrease in V/Q-ratio in the dorsal region during hyperoxia $(p=0.04)$. Two subjects did not reach a tcPO $\mathrm{PO}_{2}$ of $60 \mathrm{kPa}$ despite breathing $100 \%$ oxygen.

\section{Conclusion}

These results indicate that breathing increased concentrations of oxygen induces pulmonary vasodilatation in the dorsal lung even at small increases in $\mathrm{F}_{\mathrm{i}} \mathrm{O}_{2}$. Ventilation remains unchanged. Local mismatch of ventilation and perfusion occurs in young healthy men and the change in ventilation/perfusion ratio can be determined noninvasively by EIT.

Key words: Acute hyperoxia, EIT, lungs, perfusion, ventilation, dose-response, V/Q ratio 


\section{Introduction}

Despite the physiological and clinical importance of oxygen, the detailed mechanisms behind its vascular effects are still largely unknown. In most tissues low arterial oxygen pressure $\left(\mathrm{P}_{\mathrm{a}} \mathrm{O}_{2}\right)$ causes vasodilatation and high $\mathrm{P}_{\mathrm{a}} \mathrm{O}_{2}$ vasoconstriction ${ }^{1-2}$. The inhalation of increased oxygen fractions $\left(\mathrm{F}_{\mathrm{i}} \mathrm{O}_{2}\right)$ is reported to momentarily induce vasoconstriction in the brain ${ }^{3}$, skeletal muscle ${ }^{4}$, myocardium ${ }^{5}$ and retina ${ }^{6}$ without major changes in stroke volume ${ }^{7}$.

The reported effects of oxygen on pulmonary circulation and perfusion are conflicting. Increased $\mathrm{F}_{\mathrm{i}} \mathrm{O}_{2}$ decreases mean pulmonary arterial pressure ${ }^{8-9}$. A significant increase in pulmonary perfusion in healthy volunteers after 5 min of inhaling pure oxygen has been reported ${ }^{10}$, while others showed no significant change in pulmonary perfusion after 10 minutes breathing $100 \%$ oxygen ${ }^{11}$. Accordingly, the reported effects of normobaric hyperoxia on pulmonary ventilation are contradictive; from no response ${ }^{12}$, to slight ${ }^{13-14}$, or $>50 \%$ increase ${ }^{15}$. Inequality of ventilation-perfusion (V/Q) exists in the normal lung with apical values (3) higher than basal ones (0.6). An invasive study on young healthy volunteers showed no evidence of pulmonary shunt $(\mathrm{V} / \mathrm{Q}=0)$ when breathing air, but significant shunting when breathing $100 \%$ oxygen ${ }^{16}$.

Thoracic electrical impedance tomography (EIT) is a non-invasive, radiation-free imaging technique based on the detection of dynamic changes in thoracic impedance, based on the principle that increased amounts of air (lung: $7 \Omega \mathrm{m}$ at expiration, $23 \Omega \mathrm{m}$ at inspiration ${ }^{17}$ ) increase impedance while increased amounts of fluid (blood: $1.5 \Omega \mathrm{m}$ ) cause a decrease. Multi-electrode techniques and modern image processing, first described in the late 1980's ${ }^{18}$, have made regional tomographic imaging of impedance changes possible. Changes in the amount of pulmonary air during the respiratory cycle, have been shown to be proportional to the magnitude of change in thoracic impedance from end-expiration to endinspiration. Recent reviews ${ }^{19-21}$ state that ventilation monitoring using EIT is on the verge of clinical use at the bedside, especially in intensive care units. Pulmonary perfusion (i.e. delivery of arterial blood to the pulmonary capillary bed) imaging with EIT is more of a challenge, largely due to smaller impedance changes ${ }^{19}$. The bulk of studies have been done measuring the pulsatility of the cyclic magnitude of perfusion-related impedance signals using ECG-gated methods, frequency domain filtering and principal component analyses. Cardiac-cycle-related blood volume changes in the small pulmonary vessels significantly contribute to the magnitude of EIT pulsatility, i.e. pulmonary impedance-changes during the heart cycle where an increase in absolute magnitude (larger decrease in impedance during systole) is 
associated with increased regional pulmonary blood volume ${ }^{14}$. Being sensitive to changes in the pulmonary microvascular bed ${ }^{22}$, but not, for example, to pulmonary artery distensibility ${ }^{23}$, pulsatility has been suggested as a preferred method for pulmonary vascular response and perfusion studies ${ }^{19}$. The method still suffers from lack of consensus on standard protocols and equipment and controversy remains, regarding the influence of stroke volume ${ }^{22-24}$ and its applicability to the injured lung $25-26$.

The simultaneous assessment of changes in impedance related to pulmonary ventilation $\left(\Delta Z_{V}\right)$ and perfusion $\left(\Delta Z_{Q}\right)$ is attractive. Fagerberg et al. $2009{ }^{14}$ described in a porcine model how EIT can be used to monitor global changes in $\Delta \mathrm{Z}_{\mathrm{Q}}$ with adequate precision during acute variations in cardiac preload by averaging changes in pulsatile perfusion impedance. Using the same model and EIT technique, they successfully combined monitoring of the distribution of pulmonary ventilation and perfusion ${ }^{24}$. The tomographic imaging technique together with improved spatial resolution from an increased number of electrodes ${ }^{17}$ opens up for regional detailed studies on changes in V/Q matching.

To our knowledge, the effect of breathing increasing oxygen fractions on global and regional pulmonary ventilation, perfusion and the associated change in V/Q ratio have not been reported. The aim of the present study, based on the findings of Fagerberg et al. ${ }^{14,24}$, was to assess the mid-thoracic global and regional pulmonary changes in $\Delta \mathrm{Z}_{\mathrm{V}}$ and $\Delta \mathrm{Z}_{\mathrm{Q}}$ at increasing levels of hyperoxia in healthy male volunteers. 


\section{Methods}

\section{Subjects}

Twelve healthy male non-smokers without medication, aged 28(4) years [mean(SD)], height 179(6) cm, body weight $76(13) \mathrm{kg}$, and body mass index $23(3.6) \mathrm{kg} / \mathrm{m}^{2}$, gave informed consent to participate. After 12 caffeine-free hours measurements started at $10.00 \mathrm{am} \pm 1.5$ hours. None of the volunteers had skin wounds or scars on the thorax and all tolerated electrode material and tape well. The study was approved by the Regional Ethics Committee (Linköping, Sweden Dnr M84-09).

\section{Procedures and oxygen titration}

With the volunteers lying semi-supine on a bed, a tight-fitting face mask attached to a Servo-I ventilator (Maquet Critical Care, Solna, Sweden) was applied. Normal breathing was supported by a slight positive pressure $\left(+1 \mathrm{cmH}_{2} \mathrm{O}\right)$. Tidal volume $\left(\mathrm{V}_{\mathrm{T}}\right)$ and airway flow were recorded by a dedicated acquisition system (NICO, Novametrix Medical Systems; Wallingford, CT). A transcutaneous oxygen sensor (TINA, Radiometer, Copenhagen, Denmark) was placed $2 \mathrm{~cm}$ to the left of the umbilicus in order to monitor arterial oxygen partial pressures $\left(\mathrm{tcPO}_{2}\right)$. Calibration was performed prior to the experiment according to the manufacturer's instructions. Mean blood pressure was measured noninvasively at the beginning and the end of the experiment using a sphygmomanometer.

Heart-rate was registered using a single-lead electrocardiogram (ECG), later used for cardiac pulse gated averaging of the EIT signal. Thirty-two self-adhesive dedicated electrodes were positioned at equal intervals around the thorax at the mid-thoracic level half way between the armpit and the xiphoid process and connected to the EIT monitor Enlight ${ }^{\circledR}$ (Dixtal Biomédica Ltda., São Paulo, Brazil). So as to avoid subdiaphragmatic registration images were checked to ensure delivery of ventilatory data from all areas of the thorax apart from the heart and large vessels. During an acclimatisation period of at least 30 minutes breathing room temperature air via the face-mask, 20 seconds breath-holding training was performed. Thereafter the experiment and EIT registration began (Figure 1). The normobaric $\mathrm{F}_{\mathrm{i}} \mathrm{O}_{2}$ was adjusted every 15 minutes in order to obtain $\mathrm{tcPO}_{2}$ levels of 20,40 and $60 \mathrm{kPa}$ respectively. The last 5 minute period at each $t c \mathrm{PO}_{2}$ was used for $\mathrm{F}_{\mathrm{i}} \mathrm{O}_{2}$ titration up to the next $\mathrm{tcPO}_{2}$ level, as described previously ${ }^{27}$. At each new level, thoracic impedance was monitored during tidal volume breathing for 3 minutes (for "ventilation mode analysis"). For "perfusion mode analysis" of pulse-related impedance variations the volunteers twice randomly stopped breathing for 20 seconds. The $\mathrm{F}_{\mathrm{i}} \mathrm{O}_{2}$ levels applied were not randomised, as this would have required long washout periods, but the subjects were unaware of the 
gas mixture they were breathing.

\section{EIT}

EIT data were acquired using the Enlight platform (Experimental Pulmonology Laboratory and Polytechnic Institute, University of São Paulo \& Dixtal Biomédica Ltda., São Paulo, Brazil) ${ }^{28-29}$. The equipment produces 50 impedance-based images per second from the 32 electrodes by emitting small electric currents $(5 \mathrm{~mA} ; 125 \mathrm{kHz})$ in a rotating sequence through pairs of electrodes, with one interposed non-emitting detection electrode. One "raw voltage frame" representing 928 voltage measurements was reconstructed in an algorithm based on a sensitivity matrix derived from a 3D finite element model. A relative impedance image with slice thickness of $\approx 6 \mathrm{~cm}$ is produced, comparing the most recent raw voltage frame with the reference frame (mean of the first 300 frames i.e. recordings at normobaric $\mathrm{FiO}_{2}$ in this study). The output pixel values in each image represent percentage changes in local tissue impedance. In the "ventilation mode" the tidal oscillations reflects tissue aeration and in the "perfusion mode" the pulse oscillations reflect tissue perfusion ${ }^{30}$. The magnitude of these oscillations $(\Delta \mathrm{Z})$ for a fixed pixel are calculated using ventilation-gated ( $3 \mathrm{~min})$ and ECG-gated ( $2 * 20 \mathrm{sec}$ apnea) averaging, used for regional ventilation and perfusion assessment (Figure 2).

The EIT signal analysis includes a tool based on Matlab R2007b (The Mathworks Inc., Natick, MA). For each relative image, the changes in cyclic impedance for individual pixels within each region of interest (ROI) are summed, and a relative impedance signal, $\Delta \mathrm{Z}(\mathrm{t})$, is derived for each $\mathrm{ROI}$ at a sampling rate of $50 \mathrm{~Hz}$. The impedance signals consist of a strong $0.1-0.3 \mathrm{~Hz}$ ventilation component, and a weaker $0.9-$ $1.3 \mathrm{~Hz}$ superimposed component from perfusion and random noise. With the ventilation acquisition system as a trigger, gating and averaging of the regional maximum air volume is performed...

\section{ROI analysis}

ROIs were defined separately for each subject. Changes in heart and large vessel blood volume were recognised in real-time impedance perfusion images as areas with pulsations out of phase. A vertical boundary was defined to completely exclude the heart and large vessels. Thereafter one ventral and one dorsal right lung ROI was maintained throughout the study (Figure 3).

Ventilation and Perfusion analyses (Figure 2).

For ventilation mode, the averaged ventilation-gated first 3 minutes of each acquisition (18-45 breathing 
cycles) gave single arbitrary unit impedance breathing cycles with the magnitude of "tidal impedance change" $\left(\Delta \mathrm{Z}_{\mathrm{V}}\right)$. The spirometric $\mathrm{V}_{\mathrm{T}}$ was averaged and the magnitude of changes calculated.

For perfusion mode results, a single, signal-averaged ECG-gated impedance tracing was obtained during two separate 20 -sec periods of apnea (18-26 cardiac cycles each) and pulmonary perfusion $\left(\Delta \mathrm{Z}_{\mathrm{Q}}\right)$ was assessed using the maximum change (magnitude) in impedance during the cardiac cycle.

\section{V/Q ratio}

The $V / Q$ ratio was estimated as $\left(\Delta \mathrm{Z}_{\mathrm{V}} \times\right.$ respiratory rate $) /\left(\Delta \mathrm{Z}_{\mathrm{Q}} \times\right.$ heart rate). The mean respiratory and heart rates were calculated from the ventilator and ECG during periods used for EIT calculations.

\section{Statistics}

Statistical calculations were performed using GraphPad Prism (v5.00 for Windows, GraphPad Software, San Diego California USA, "www.graphpad.com") and MedCalc (v11.1.1.0 for Windows, MedCalc Software BVBA, Belgium). Due to abnormally distribution of data and limited power of nonparametric repeated measure tests for small samples, impedance data were transformed logarithmically to normalise the distribution ${ }^{31}$ prior to comparison. Mean and standard deviation (SD) values were calculated and when graphically presented standard error of the mean (SEM) was added. Repeated measures analyses of variance (ANOVA) were used to test for significant changes in logarithmically normalised values at each tcPO2 level. In case of significance the Bonferroni's post-hoc multiple comparison tests and linear regression analysis were applied. Correlation between spirometric and impedance data was assessed by calculating Pearson's r-values. A $p$-value $<0.05$ was regarded as significant. 


\section{Results (Table 1 and 2)}

Tidal volume, flow, heart rate and ventilation rate did not change significantly with $\mathrm{cPO}_{2}$ levels. There was an overall correlation between tidal $\mathrm{V}_{\mathrm{T}}$ and $\Delta \mathrm{Z}_{\mathrm{v}}$ (Pearson's $r 0.59 ; p<0.001$ ). Mean blood pressures at the beginning and end of the experiment were similar.

The $\mathrm{tcPO}_{2}$ values at each level matched the intended (inaccuracy $<1.5 \%$ ). Two subjects did not reach the highest $\mathrm{tcPO}_{2}, 60 \mathrm{kPa}$, when breathing $100 \%$ oxygen and in 1 subject acquisition errors occurred at $40 \mathrm{kPa}$. ECG data during the apnea periods allowed reliable R-wave-detection. Incidental impedance signal artefacts from the subject's movements, or irregular or strong breathing were few and signal averaging removed those artefacts adequately resulting in typical signal averaged impedance $\Delta \mathrm{Z}_{\mathrm{V}^{-}}$and $\Delta \mathrm{Z}_{\mathrm{Q}^{-}}$time-curves.

EIT ventilation mode analysis (Figure 4).

$\Delta \mathrm{Z}_{\mathrm{V}}$ did not change significantly between tc $\mathrm{PO}_{2}$ levels (ventral $p=0.58$, dorsal $p=0.63$ ).

\section{EIT perfusion mode analysis (Figure 5)}

$\Delta \mathrm{Z}_{\mathrm{Q}}$ did not change significantly with increased tc $\mathrm{PO}_{2}$ in the ventral right lung $(p=0.80)$. In the dorsal right lung region $\Delta \mathrm{Z}_{\mathrm{Q}}$ increased significantly with increasing $\mathrm{tcPO}_{2}$ for all levels only compared to baseline $(20 \mathrm{kPa} p<0.05,40 \mathrm{kPa} p<0.05,60 \mathrm{kPa} p<0.01)$ but showed an increasing linear trend $(p=$ $0.004)$.

\section{EIT V/Q ratio (Figure 6)}

Increase in oxygen fraction did not significantly affect V/Q-ratio in the ventral lung $(p=0.70)$. In the dorsal lung, the V/Q ratio was decreased at $\mathrm{tcPO}_{2} 20 \mathrm{kPa}(p=0.04)$ and above that showed an linear falling trend $(p=0.03)$. 


\section{Discussion}

The main finding of this study on healthy young males is that EIT perfusion mode analysis indicates an increase in pulmonary perfusion when breathing increased oxygen fractions. This effect was already seen at slightly increased arterial oxygen partial pressures and supports the theory of hyperoxia-induced pulmonary vasodilation. Regional analysis shows that this effect is significant only in the dependent/dorsal parts of the lungs, where a decrease in V/Q-ratio also occurs with increasing $\mathrm{PO}_{2}$ gradient, indicating increased ventilation-perfusion mismatch.

An increase in arterial oxygen partial pressure had no effect on pulmonary ventilation, respiratory rate or heart rate in this study. Previous studies have shown that breathing oxygen-enriched air transiently (2-3 minutes) decreases minute ventilation by $10-20 \%$ before returning to baseline ${ }^{32}$. Thereafter no or only mild ventilation effects have been reported in healthy subjects breathing increased fractions of oxygen for up to 1 hours ${ }^{7,11-12,15,27}$ which is further confirmed in this study where measurements started about 5 minutes after the inspiratory fraction of oxygen had been increased. Hyperoxic breathing has been reported to reduce the partial pressure of alveolar carbon dioxide $\left(\mathrm{CO}_{2}\right)^{33-35}$. End-tidal $\mathrm{CO}_{2}$-pressure was not measured in this study but we have previously shown in the same setup that $t c \mathrm{PCO}_{2}$ remained unchanged when breathing increased oxygen fractions ${ }^{27}$. Becker et al. ${ }^{13}$ however reported that ventilation increased only by $16 \%$, when end-tidal $\mathrm{CO}_{2}$ partial pressure decreased significantly in healthy subjects while breathing hyperoxic mixtures, compared to a $>50 \%$ increase in ventilation when isocapnia was maintained ${ }^{15}$.

We choose to study healthy young male adults to avoid confounding effects of gender, specifically thoracic anthropometric parameters that could potentially affect EIT perfusion results ${ }^{36}$, whereas ventilation data are less influenced ${ }^{37}$. Healthy youngsters were chosen in order to exclude errors due to lung pathology 25 or basal atelectasis during normal tidal breathing. In healthy young spontaneously breathing supine subjects, ventilation is more pronounced in the dorsal dependent parts, as is perfusion where gravity effects are even greater $(\mathrm{V} / \mathrm{Q}<$ normal global 0.8$)$. The anterior lung is less well ventilated and perfused but fairly matched $(\mathrm{V} / \mathrm{Q}>0.8)^{16}$. In this study adequate V/Q-matching when breathing normal air was confirmed by a normal tcPO2. When a lung-region is poorly ventilated, local alveolar hypoxia causes precapillary vasoconstriction, while hyperoxia causes vasodilatation. Our finding of an increased dorsal pulmonary perfusion and a relative decrease in regional V/Q without ventilatory changes indicates a hyperoxia-induced change in V/Q-ratio, where mismatch is further 
supported by increase in $\mathrm{PO}_{2}$ gradient. Indeed, the tcPO2 did not reach $60 \mathrm{kPa}$ in all subjects, despite an $\mathrm{F}_{\mathrm{i}} \mathrm{O}_{2}$ of $100 \%$.

Already in the 1970's induction of a pulmonary shunt when breathing $100 \%$ oxygen was described in healthy volunteers ${ }^{16}$. In the late 90 's it was shown in sheep that inhalation of $40 \%$ oxygen for 10 minutes increased V/Q-mismatch, which returned to baseline after 2.5 hours ${ }^{38}$. The cause of these findings was a redistribution of perfusion, while there was no change in ventilation, which confirms our noninvasive findings using EIT in this study. Furthermore during hyperoxia increases in pulmonary blood flow and artery pressure ${ }^{39}$ as well as increases in and redistribution of pulmonary perfusion, predominately occur in dependent regions ${ }^{10}$. Our findings show a mean $19 \%$ increase in overall pulmonary perfusion and a $45 \%$ increase in posterior regions. In contrast to the studies cited above and our results, others report no significant immediate effect of normobaric hyperoxia on vascular resistance or $Q$ in the normal human lung. The experimental setup evaluating the effect of unilateral inhalation of $100 \%$ oxygen during contralateral normoxia ${ }^{40}$ EIT with lesser resolution, unknown $\mathrm{P}_{\mathrm{a}} \mathrm{O}_{2}$ levels, different ROI positions and timing after $>10$ minutes of breathing $100 \%$ oxygen ${ }^{11}$ might have contributed to these diverging results. Our measurements were performed about 5 minutes after an increase in $\mathrm{F}_{\mathrm{i}} \mathrm{O}_{2}$ with rapid response. Further studies are required to determine the pattern and duration of these regional pulmonary vascular effects.

Recent ventilation and perfusion studies based on cyclic impedance EIT changes lack consistent protocols using standard available equipment ${ }^{19}$. Cardiac-related impedance changes are inherently of lower amplitude and higher frequency than the changes due to ventilation, making them more challenging to detect. Various approaches have been used to isolate ventilation and perfusion signals from the raw impedance signal, including frequency filtering techniques, signal averaging techniques ${ }^{23}$ and breath-holding manoeuvres ${ }^{19}$ as in this study. In spontaneous breathing, which is more challenging for EIT measurements than controlled mechanical ventilation, frequency filtering is equally effective as breath-holding in separating ventilation from perfusion ${ }^{41}$. Nevertheless, in most subjects we found an adequate correlation between the averaged changes in $\mathrm{V}_{\mathrm{T}}$ as measured by EIT and NICO, in agreement with previous EIT ventilation validation studies ${ }^{37,42}$. We used a 32-lead prototype programmed for $5 \mathrm{~mA}$ $125 \mathrm{kHz}$ currents to be emitted while most commercially available equipment use $5 \mathrm{~mA}$ and $50 \mathrm{kHz}$ as this frequency reduces electrode-skin impedance considerably. Even lesser magnitude especially of cardiacrelated impedance changes with inherently lower amplitude and faster changes than the changes due to 
ventilation have been reported at higher frequencies ${ }^{18}$. When filtered from simultaneous ventilation cycles, larger numbers of heart beats averaged ${ }^{19}$ are usually reported than the number we used. Apnea and higher sampling rate reduce the variation and motivate the lower number used..

\section{Limitations of this study}

No consensus exists on the influence of heart stroke volume on $\Delta \mathrm{Z}_{\mathrm{Q}}{ }^{14,22-23}$. In this setting we have previously reported a $<20 \%$ decrease in cardiac output when breathing increasing fractions of oxygen, due to decreased heart rate ${ }^{7}$ or stroke volume ${ }^{27}$. In this study stroke volume was not recorded but heart rate did not change. An increase in $\Delta \mathrm{Z}_{\mathrm{Q}}$ (vasodilatation/blood volume is known to be a major cause), as recorded in the dorsal right lung in this study, cannot be explained by a decrease in stroke volume. The influence of stroke volume and cardiac output and the potential physiological influences of tidal volume on the pulmonary vasculature, that wereeliminated by the breath-holding manoeuvre, have to be studied using other methods and algorithms. The limited and different peripheral and central (lens-shaped) spatial resolution, inherent with EIT, may increase the sensitivity to motion artefacts in the periphery. This is particularly so in the dorsal ROI with larger changes in lung volume during breathing and the use of 32 electrodes which increases the cross-sectional resolution (from $12 \%$ of the thoracic diameter peripherally and $20 \%$ centrally in the 16 electrode system to $6 \%$ and $10 \%$ respectively ${ }^{29}$ ).We did not quantitatively validate our EIT measurements neither accuracy nor reproducibility, which is why precision and bias are unknown. The reproducibility of $\Delta Z_{v}$ measurements has previously been reported to be $4,9-7,4 \%$ with or without repositioning of the electrodes ${ }^{29}$, but has not to our knowledge been reported for $\Delta \mathrm{Z}_{\mathrm{Q}}$. Our data show large individual variations and individual reactions to oxygen. It is well known that the normal human response to both acute and long-term hyperoxia show large vascular but also ventilatory inter- and intra-individual variations ${ }^{43}$. This may partly explain the sometimes conflicting results seen both in literature and in our data where, for example, some subjects did not reach the $\mathrm{tcPO}_{2}$ goal $60 \mathrm{kPa}$, when breathing $100 \%$ oxygen. This EIT prototype records cyclic changes in impedance with ventilation and perfusion and cannot be translated to units of these parameters at any specific point in time. Future reproducibility studies based on strict protocols are needed.

The EIT-system, however, has been used with success in previous studies ${ }^{19,23,28}$ but when signs of lung pathology are present the accuracy of both $\Delta \mathrm{Z}_{\mathrm{V}}$ and $\Delta \mathrm{Z}_{\mathrm{Q}}$ using this prototype has recently been questioned ${ }^{25}$. The significant changes we report are relative in nature and follow a trend that strengthens our results. A cardiac contour ROI is reported superior for the removal of impedance interference from 
the heart ${ }^{11}$, and modern image segmentation techniques with phase filtering and out of phase pattern recognition would be of advantage instead of a few inflexible ROIs as used in this prototype setting. The thoracic level chosen included the 6th intercostal space where the heart is known to most severely influence the thoracic EIT. This was recognised and we excluded both out of phase and left quadrant data from further analysis. The use of increasing numbers of electrodes improves spatial resolution ${ }^{24}$ and vouches for improved regional analysis in the future.

Care should be taken when choosing a particular technique as beeing the "gold standard" against which the EIT method is validated ${ }^{22}$ as it uniquely registers dynamic regional changes in lung volume and blood volume in the pulmonary vessels. This EIT technique does not yield measures of blood flow in and out of the pulmonary vascular bed, rather changes in impedance arising from the changes in blood volume in the pulmonary vasculature during the cardiac cycle. A change in pulmonary blood flow or vascular size is not a prerequisite and factors such as compliance, vascular resistance and transmural pressure may also have been affected by the changes in partial oxygen pressure in this study. A first-pass kinetic indicator dilution technique is suggested to improve pulsatile pulmonary perfusion impedance EIT estimates but further confirmatory studies are required ${ }^{25,44}$.

\section{Conclusion}

We report, for the first time, the effects of hyperoxia on regional and global pulmonary ventilation and perfusion in healthy male volunteers using non-invasive EIT-monitoring. The cardiac cycle-related changes in impedance observed occurs at even small increase in $\mathrm{P}_{\mathrm{a}} \mathrm{O}_{2}$, probably indicating regional pulmonary vasodilatation predominantly in the dependent regions of the lungs. Pulmonary ventilation is unaffected by $\mathrm{P}_{2} \mathrm{O}_{2}$. These effects combined indicate a local mismatch between ventilation and perfusion caused by an increase in $\mathrm{P}_{\mathrm{a}} \mathrm{O}_{2}$ in healthy young men. Such changes in ventilation/perfusion ratio are readily determined noninvasively using the EIT technique. 


\section{Acknowledgements}

We thank Josep Solà, PhD, Senior R\&D Engineer at CSEM, Neuchâtel, Switzerland for his technical advice. Financial support was obtained from the County Council of Östergötland and Karolinska Institutet in Stockholm, Sweden.

\section{Competing interests}

SH Böhm is co-founder of Swisstom AG and its Medical Director. He filed several patents on EIT. Otherwise the authors declare that they have no conflicting interests. 


\section{Figures:}

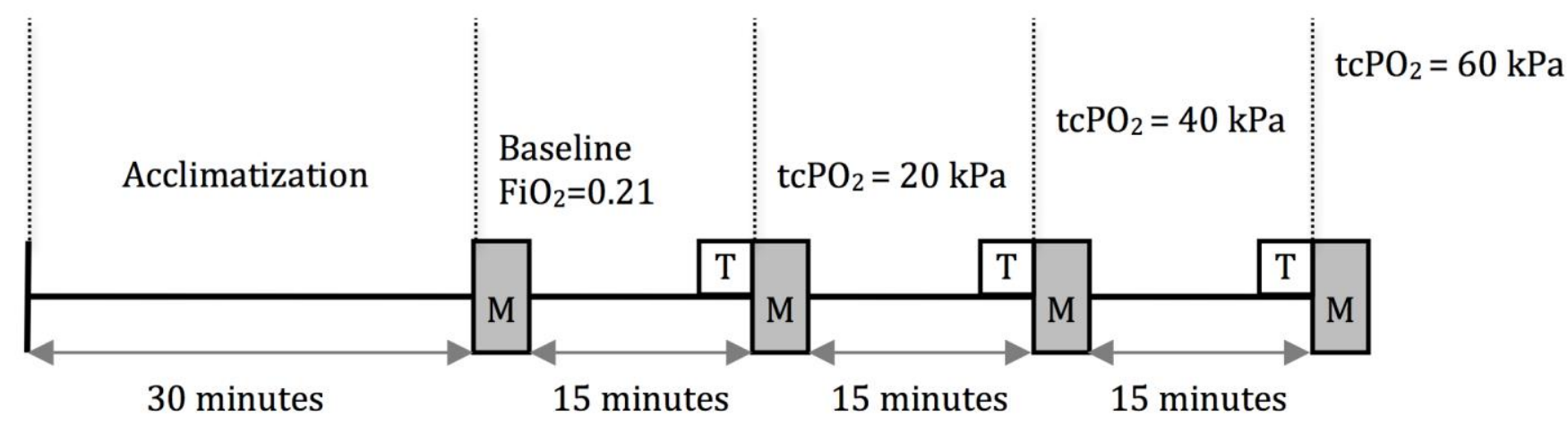

Figure 1: Experimental setup. After an acclimatisation period with the facemask, baseline recordings were achieved while breathing air $\left(\mathrm{F}_{\mathrm{i}} \mathrm{O}_{2} 21 \%, \mathrm{tcPO}_{2} 8 \mathrm{kPa}\right) . \mathrm{F}_{\mathrm{i}} \mathrm{O}_{2}$ was thereafter titrated (T) over $<5$ minutes to reach the predetermined $\mathrm{tcPO}_{2}$ value $(20,40$ and $60 \mathrm{kPa})$, after which measurements $(\mathrm{M})$ were performed during a 3-minute period, including two periods of 20 sec. apnea. $\mathrm{F}_{\mathrm{i}} \mathrm{O}_{2}$-titration and measurements were repeated every 15 minutes. 


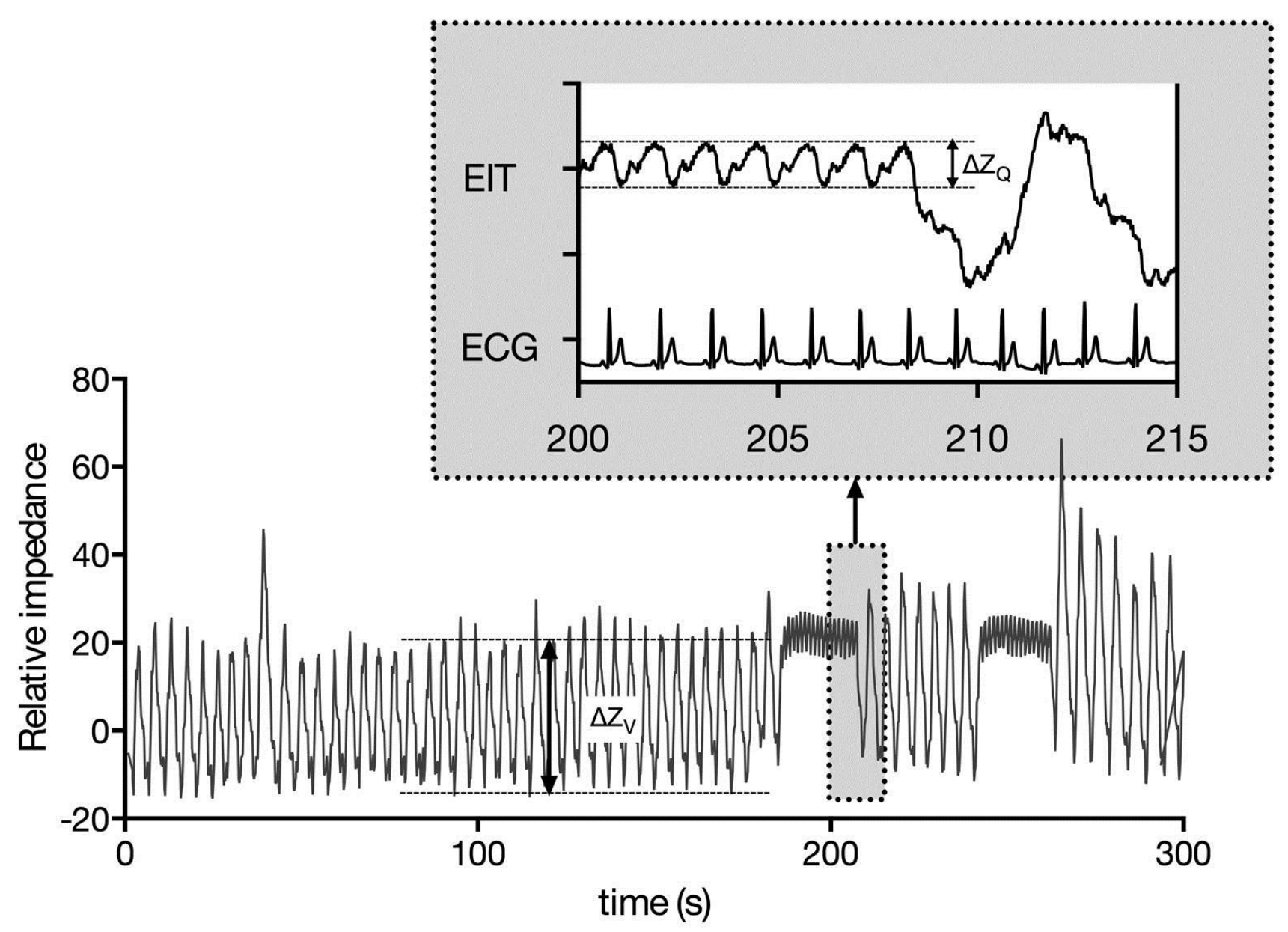

Figure 2: A typical impedance tracing at baseline, showing change in impedance with time for the total lung. The ventilation and perfusion components are clearly seen (see inset). Data are collected for 5 minutes. After 3 and 4 minutes, the subject stopped breathing for 20 seconds. The data obtained during breath-holding were used to analyse the perfusion component. $\Delta \mathrm{Z}_{\mathrm{V}}$ and $\Delta \mathrm{Z}_{\mathrm{Q}}$ were defined as the mean amplitude of the ventilation and perfusion tracings (as indicated by double-arrows), averaged over a number of breaths or heart beats. 


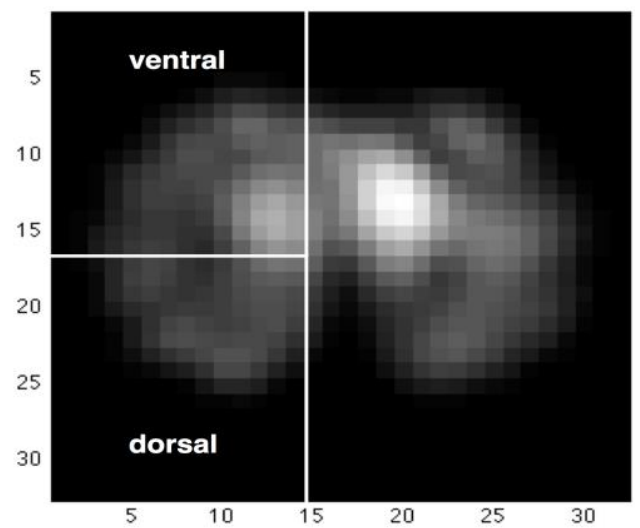

Figure 3: Typical EIT perfusion image showing a region with high perfusion signal corresponding to the heart. Two regions of interest, the ventral and dorsal regions of the right lung (completely excluding the heart), were defined for each subject, and maintained for measurements at the three $\mathrm{tcPO}_{2}$ levels. 


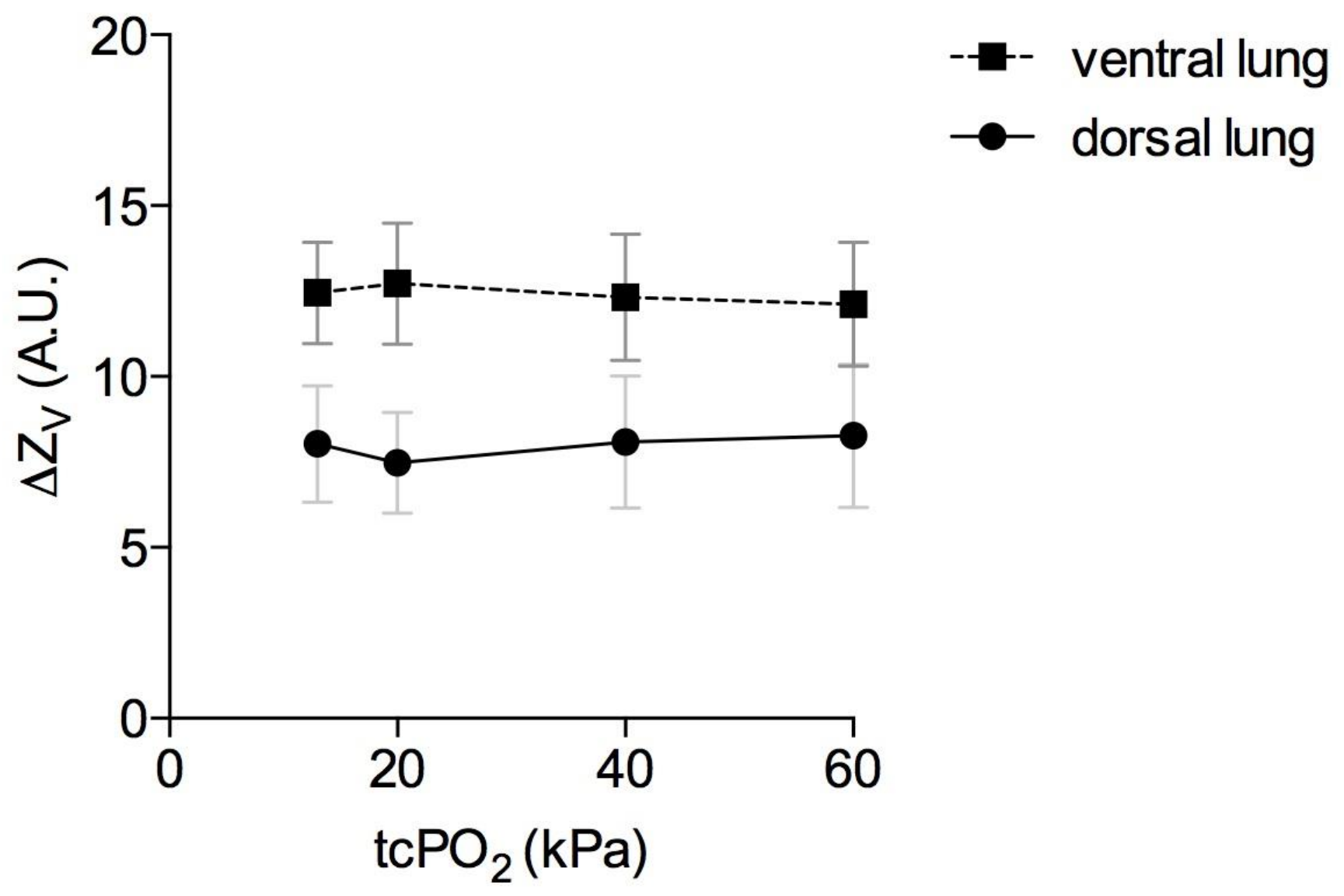

Figure 4: Ventilation-related change in impedance $\left(\Delta \mathrm{Z}_{\mathrm{V}}\right)$ at the tcPO $\mathrm{PO}_{2}$ levels as measured by EIT. $\Delta \mathrm{Z}_{\mathrm{V}}$ did not differ significantly at different tc $\mathrm{PO}_{2}$ levels, neither in the dorsal nor the ventral lung regions (ventral: $p=0.58$, dorsal: $p=0.63$ ). 


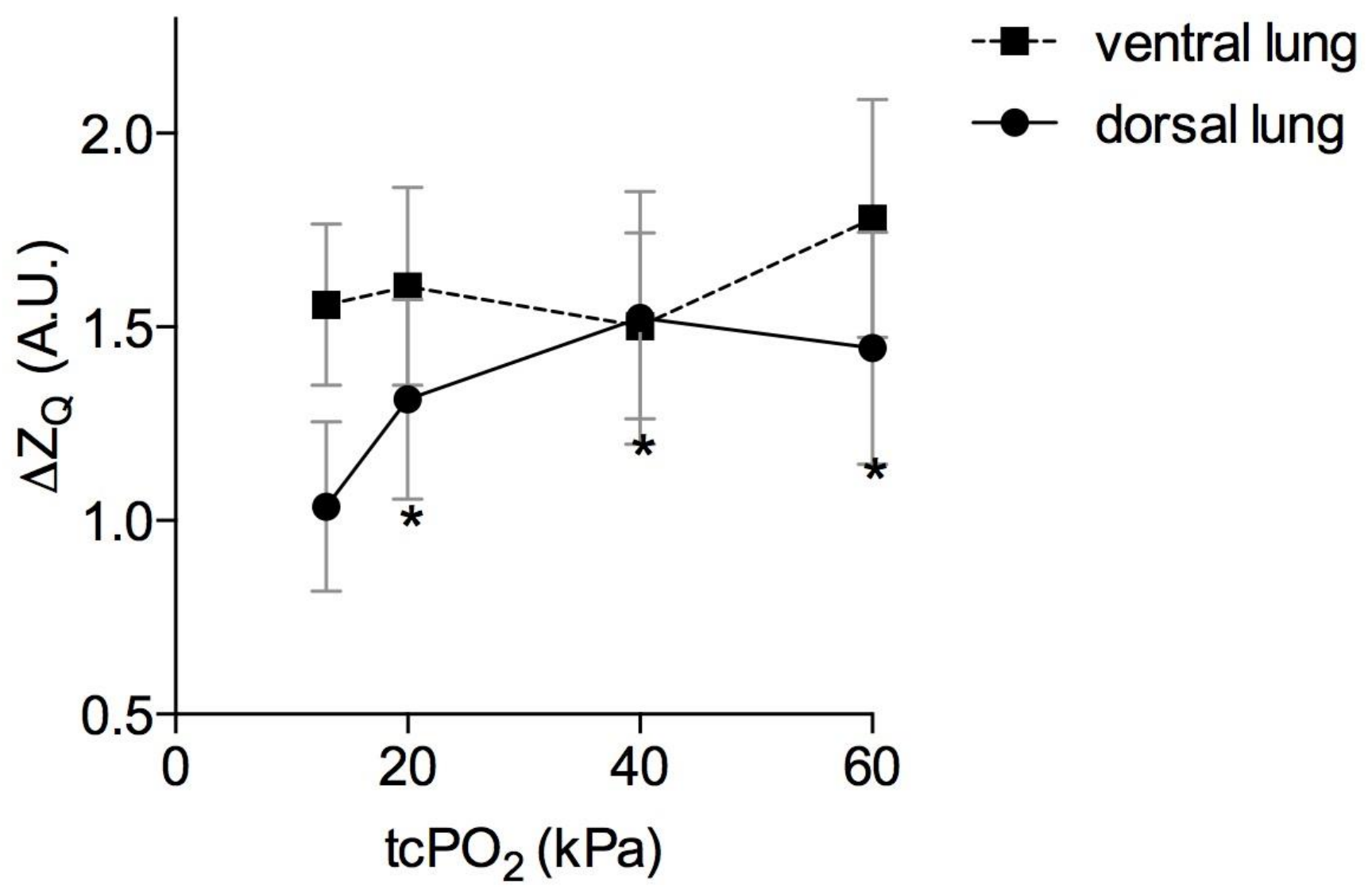

Figure 5: Perfusion-related changes in impedance $\left(\Delta \mathrm{Z}_{\mathrm{Q}}\right)$ at the $\mathrm{tcPO}_{2}$ levels as measured by EIT. $\Delta \mathrm{Z}_{\mathrm{Q}}$ in the dorsal lung increased in proportion to the $\mathrm{tcPO}_{2}(* p<0.05$ compared to baseline). 


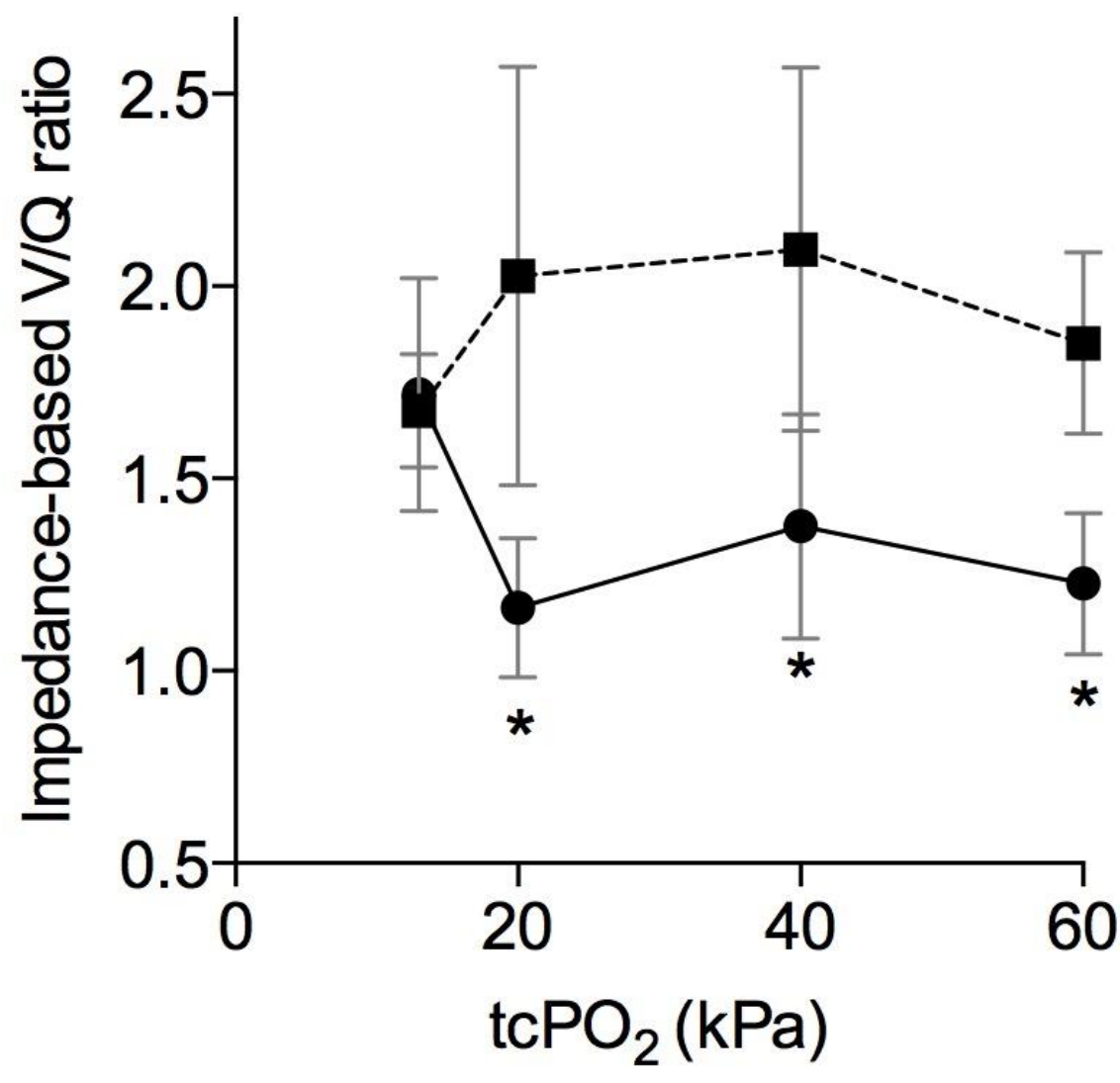

Figure 6: V/Q ratios, defined as $\left[\Delta \mathrm{Z}_{\mathrm{V}} \times\right.$ respiratory rate $] /\left[\Delta \mathrm{Z}_{\mathrm{Q}} \times\right.$ heart rate $]$ at the tc $\mathrm{PO}_{2}$ levels as measured by EIT. A significant effect of $\mathrm{tcPO}_{2}$ was found in the dorsal lung, where V/Q decreased with $\mathrm{tcPO}_{2}(* p<0.05$ compared to baseline). 


\section{Tables}

Table 1. A summary of results [mean (SD)] from twelve healthy young males.

\begin{tabular}{|c|c|c|c|c|}
\hline & Baseline $(n=12)$ & $20 \mathrm{kPa}(\mathrm{n}=12)$ & $40 \mathrm{kPa}(\mathrm{n}=11)$ & $60 \mathrm{kPa}(\mathrm{n}=10)$ \\
\hline \multicolumn{5}{|l|}{ Oxygen } \\
\hline $\mathrm{FiO}_{2}(\%)$ & $0.21^{\#}$ & $0.49(0.11)$ & $0.72(0.07)$ & $0.94(0.07)$ \\
\hline $\mathrm{tcPO}_{2}(\mathrm{kPa})$ & $11.6(1.8)$ & $20.3(0.4)$ & $40.2(0.7)$ & $60.1(0.5)$ \\
\hline \multicolumn{5}{|l|}{ Ventilation } \\
\hline respiratory rate $\left(\min ^{-1}\right)$ & $12.1(3.8)$ & $12.2(3.9)$ & $12.6(3.8)$ & $12.4(3.0)$ \\
\hline airway flow (L/min) & $62.2(10.5)$ & $65.2(9.2)$ & $67.2(11.8)$ & $68.4(11.4)$ \\
\hline $\mathrm{V}_{\mathrm{T}}(\mathrm{mL})$ & $892(291)$ & $951(292)$ & $1078(628)$ & $982(229)$ \\
\hline ventral $\Delta \mathrm{Z}_{\mathrm{V}}$ (a.u.) & $12.5(5.2)$ & $12.7(6.1)$ & $14.9(10.1)$ & $12.1(5.7)$ \\
\hline dorsal $\Delta \mathrm{Z}_{\mathrm{V}}$ (a.u.) & $8.3(7.2)$ & $8.1(6.7)$ & $7.5(4.9)$ & $8.0(5.4)$ \\
\hline \multicolumn{5}{|l|}{ Perfusion } \\
\hline $\operatorname{HR}\left(\min ^{-1}\right)$ & $62 \pm 8$ & $60 \pm 6$ & $61 \pm 4$ & $63 \pm 4$ \\
\hline MAP (mmHg) & $86 \pm 8$ & & & $85 \pm 5$ \\
\hline ventral $\Delta \mathrm{Z}_{\mathrm{Q}}$ (a.u.) & $1.6(0.8)$ & $1.7(1.1)$ & $1.8(1.4)$ & $1.9(1.2)$ \\
\hline dorsal $\Delta \mathrm{Z}_{\mathrm{Q}}$ (a.u.) & $1.0(0.7)$ & $1.3(0.9)^{*}$ & $1.5(1.1)^{*}$ & $1.4(0.9)^{*}$ \\
\hline \multicolumn{5}{|l|}{ Impedance-based V/Q ratio } \\
\hline ventral V/Q-ratio (a.u.) & $1.7(0.5)$ & $2.0(1.8)$ & $2.1(1.4)$ & $1.9(0.7)$ \\
\hline dorsal V/Q-ratio (a.u.) & $1.7(1.0)$ & $1.2(0.6)^{*}$ & $1.4(0.9)^{*}$ & $1.2(0.6)^{*}$ \\
\hline
\end{tabular}

Abbreviations: $\mathrm{FiO}_{2}=$ inspired $\mathrm{O}_{2}$ fraction; ( ${ }^{\#}$ preset value); $\mathrm{tcPO}_{2}=$ transcutaneous $\mathrm{O}_{2}$ partial pressure; $\mathrm{HR}=$ heart rate; $\mathrm{MAP}=$ mean arterial pressure $; \mathrm{V}_{\mathrm{T}}=$ tidal volume; $\Delta \mathrm{Z}_{\mathrm{V}}=$ magnitude in arbitrary units (a.u.) of cyclic ventilation-related EIT pulsations; $\Delta \mathrm{Z}_{\mathrm{Q}}=$ magnitude in arbitrary units (a.u.) of cyclic perfusion-related EIT pulsations; $\mathrm{V}=$ ventilation; $\mathrm{Q}=$ perfusion. $* p<0,05$ compared to baseline ( $\mathrm{n}=9$ for ventral $\Delta \mathrm{Z}_{\mathrm{V}}$, and ventral and dorsal V/Q ratios; $\mathrm{n}=10$ for dorsal $\Delta \mathrm{Z}_{\mathrm{V}}$, ventral and dorsal $\Delta \mathrm{Z}_{\mathrm{Q}}$ ). 
Table 2. Individual data in arbitrary units (a.u.) of cyclic-related EIT pulsations.

\begin{tabular}{|c|c|c|c|c|c|c|c|}
\hline \multicolumn{8}{|c|}{ Ventilation } \\
\hline \multicolumn{2}{|c|}{ baseline } & \multicolumn{2}{|c|}{$20 \mathrm{kPa}$} & \multicolumn{2}{|c|}{$40 \mathrm{kPa}$} & \multicolumn{2}{|c|}{$60 \mathrm{kPa}$} \\
\hline ventral & dorsal & ventral & dorsal & ventral & dorsal & ventral & dorsal \\
\hline 6.0 & 6.7 & 6.9 & 8.0 & 6.1 & 7.1 & 6.0 & 6.6 \\
\hline 11.0 & 5.9 & 17.9 & 5.0 & 15.9 & 4.8 & - & - \\
\hline 15.0 & 26.4 & 14.1 & 25.0 & 7.4 & 14.0 & 9.6 & 16.3 \\
\hline 19.5 & 11.8 & 18.8 & 10.9 & 14.4 & 8.2 & 15.7 & 10.7 \\
\hline 6.9 & 5.6 & 6.5 & 8.6 & - & - & 8.6 & 8.1 \\
\hline 14.4 & 5.0 & 17.2 & 6.3 & 40.2 & 11.8 & - & - \\
\hline 14.0 & 18.3 & 13.3 & 16.2 & 16.2 & 17.1 & 15.6 & 17.7 \\
\hline 21.8 & 4.4 & 22.6 & 3.8 & 18.1 & 3.3 & 22.4 & 4.3 \\
\hline 12.7 & 1.0 & 16.9 & 1.1 & 19.8 & 1.3 & 17.4 & 1.4 \\
\hline 4.6 & 5.4 & 4.5 & 5.5 & 1.7 & 5.0 & 3.6 & 6.7 \\
\hline 13.3 & 5.0 & 5.2 & 2.7 & 14.0 & 5.5 & 12.8 & 3.7 \\
\hline 10.2 & 3.7 & 8.7 & 3.9 & 9.6 & 4.1 & 9.5 & 4.8 \\
\hline \multicolumn{8}{|c|}{ Perfusion } \\
\hline \multicolumn{2}{|c|}{ baseline } & \multicolumn{2}{|c|}{$20 \mathrm{kPa}$} & \multicolumn{2}{|c|}{$40 \mathrm{kPa}$} & \multicolumn{2}{|c|}{$60 \mathrm{kPa}$} \\
\hline ventral & dorsal & ventral & dorsal & ventral & dorsal & ventral & dorsal \\
\hline 0.91 & 2.64 & 1.60 & 3.40 & 1.55 & 3.43 & 1.45 & 3.61 \\
\hline 2.46 & 0.99 & 2.75 & 1.22 & 2.80 & 1.30 & 3.29 & 1.31 \\
\hline 0.56 & 1.49 & 0.65 & 1.85 & 0.77 & 1.95 & 0.42 & 1.60 \\
\hline 2.27 & 0.76 & 2.34 & 1.35 & 0.86 & 2.29 & 2.10 & 1.60 \\
\hline- & - & - & - & - & - & - & - \\
\hline 1.29 & 0.97 & 1.35 & 0.96 & 1.52 & 0.90 & - & - \\
\hline 1.70 & 1.86 & 1.38 & 1.61 & 2.47 & 1.62 & 2.60 & 2.26 \\
\hline 2.06 & 0.26 & 0.81 & 0.44 & 1.02 & 0.38 & 2.20 & 1.10 \\
\hline 1.90 & 0.27 & 1.50 & 0.34 & 1.55 & 0.30 & 1.27 & 0.35 \\
\hline 0.63 & 0.60 & 0.42 & 1.26 & 0.29 & 0.99 & 0.29 & 0.99 \\
\hline 1.09 & 0.45 & 1.75 & 0.50 & 1.20 & 0.45 & 1.53 & 0.39 \\
\hline 3.05 & 1.11 & 4.20 & 1.51 & 5.50 & 3.15 & 4.20 & 1.24 \\
\hline \multicolumn{8}{|c|}{ V/Q } \\
\hline \multicolumn{2}{|c|}{ baseline } & \multicolumn{2}{|c|}{$20 \mathrm{kPa}$} & \multicolumn{2}{|c|}{$40 \mathrm{kPa}$} & \multicolumn{2}{|c|}{$60 \mathrm{kPa}$} \\
\hline ventral & dorsal & ventral & dorsal & ventral & dorsal & ventral & dorsal \\
\hline 1.59 & 0.61 & 1.03 & 0.56 & 1.00 & 0.52 & 1.03 & 0.45 \\
\hline 1.33 & 1.77 & 1.61 & 1.01 & - & - & - & - \\
\hline 2.04 & 1.35 & 1.87 & 1.16 & 0.95 & 0.71 & 2.30 & 1.02 \\
\hline 1.16 & 2.10 & 1.22 & 1.22 & 3.26 & 0.70 & 1.40 & 1.26 \\
\hline- & - & - & - & - & - & - & - \\
\hline 1.16 & 0.54 & 1.20 & 0.62 & - & - & - & - \\
\hline 2.09 & 2.50 & 2.15 & 2.24 & 1.65 & 2.65 & 1.46 & 1.91 \\
\hline 2.40 & 3.84 & 7.13 & 2.21 & 5.25 & 2.57 & 2.48 & 0.95 \\
\hline 1.34 & 0.74 & 1.83 & 0.53 & 2.35 & 0.80 & 2.68 & 0.78 \\
\hline 1.95 & 2.41 & 2.77 & 1.13 & 1.25 & 1.08 & 2.57 & 1.40 \\
\hline 2.27 & 2.07 & 0.76 & 1.39 & 2.20 & 2.31 & 1.96 & 2.22 \\
\hline 1.09 & 0.97 & 0.73 & 0.73 & 0.96 & 1.05 & 0.78 & 1.05 \\
\hline
\end{tabular}




\section{References}

1. Jackson WF. Arteriolar oxygen reactivity: where is the sensor? Am J Physiol 1987; 253: H1120-6.

2. Hutchins PM, Bond RF, Green HD. Participation of oxygen in the local control of skeletal muscle microvasculature. Circ Res 1974; 40: 85-93.

3. Watson NA, Beards SC, Altaf N, Kassner A, Jackson A. The effect of hyperoxia on cerebral blood flow: a study in healthy volunteers using magnetic resonance phase-contrast angiography. Eur J Anaesthesiol 2000; 17: 152-9.

4. Crawford P, Good PA, Gutierrez E, Feinberg JH, Boehmer JP, Silber DH, Sinoway LI. Effects of supplemental oxygen on forearm vasodilation in humans. J Appl Physiol (1985) 1997; 82: 1601-6.

5. Kenmure AC, Beatson JM, Cameron AJ, Horton PW. Effects of oxygen on myocardial blood flow and metabolism. Cardiovasc Res 1971; 5: 483-9.

6. Kiss B, Polska E, Dorner G, Polak K, Findl O, Mayrl GF, Eichler HG, Wolzt M, Schmetterer L. Retinal blood flow during hyperoxia in humans revisited: concerted results using different measurement techniques. Microvasc Res 2002; 64: 75-85.

7. Rousseau A, Bak Z, Janerot-Sjoberg B, Sjoberg F. Acute hyperoxaemia-induced effects on regional blood flow, oxygen consumption and central circulation in man. Acta Physiol Scand 2005; 183: 231-40.

8. Lee SH, Rubin LJ. Current treatment strategies for pulmonary arterial hypertension. J Intern Med 2005; 258: $199-215$.

9. Weitzenblum E. The effects of controlled oxygen therapy on ventricular function in patients with stable and decompensated cor pulmonale. Am Rev Respir Dis 1989; 139: 285-6.

10. Ley S, Puderbach M, Risse F, Ley-Zaporozhan J, Eichinger M, Takenaka D, Kauczor HU, Bock M.

Impact of oxygen inhalation on the pulmonary circulation: assessment by magnetic resonance (MR)-perfusion and MR-flow measurements. Invest Radiol 2007; 42: 283-90.

11. Smit HJ, Vonk-Noordegraaf A, Marcus JT, van der Weijden S, Postmus PE, de Vries PM, Boonstra A. Pulmonary vascular responses to hypoxia and hyperoxia in healthy volunteers and COPD patients measured by electrical impedance tomography. Chest 2003; 123: 1803-9.

12. Larson CP, Jr., Severinghaus JW. Postural variations in dead space and $\mathrm{CO} 2$ gradients breathing air and O2. J Appl Physiol 1962; 17: 417-20.

13. Becker HF, Polo O, McNamara SG, Berthon-Jones M, Sullivan CE. Effect of different levels of hyperoxia on breathing in healthy subjects. J Appl Physiol (1985) 1996; 81: 1683-90.

14. Fagerberg A, Stenqvist O, Aneman A. Monitoring pulmonary perfusion by electrical impedance tomography: an evaluation in a pig model. Acta Anaesthesiol Scand 2009; 53: 152-58.

15. Becker H, Polo O, McNamara SG, Berthon-Jones M, Sullivan CE. Ventilatory response to isocapnic hyperoxia. J Appl Physiol (1985) 1995; 78: 696-701.

16. Wagner PD, Laravuso RB, Uhl RR, West JB. Continuous distributions of ventilation-perfusion ratios in normal subjects breathing air and 100 per cent O2. J Clin Invest 1974; 54: 54-68.

17. Eyuboglu BM, Brown BH, Barber DC. In vivo imaging of cardiac related impedance changes. IEEE Eng Med Biol Mag 1989; 8: 39-45.

18. Brown BH. Electrical impedance tomography (EIT): a review. J Med Eng Technol 2003; 27: 97-108.

19. Nguyen DT, Jin C, Thiagalingam A, McEwan AL. A review on electrical impedance tomography for pulmonary perfusion imaging. Physiological Measurement 2012; 33: 695-706.

20. Bodenstein M, David M, Markstaller K. Principles of electrical impedance tomography and its clinical application. Crit Care Med 2009; 37: 713-24.

21. Moerer O, Hahn G, Quintel M. Lung impedance measurements to monitor alveolar ventilation. Curr Opin Crit Care 2011; 17: 260-7.

22. Smit HJ, Vonk Noordegraaf A, Marcus JT, Boonstra A, de Vries PM, Postmus PE. Determinants of pulmonary perfusion measured by electrical impedance tomography. Eur J Appl Physiol 2004; 92: 45-9.

23. Vonk Noordegraaf A, Kunst PW, Janse A, Marcus JT, Postmus PE, Faes TJ, de Vries PM. Pulmonary perfusion measured by means of electrical impedance tomography. Physiol Meas 1998; 19: 263-73.

24. Fagerberg A, Stenqvist O, Aneman A. Electrical impedance tomography applied to assess matching of 
pulmonary ventilation and perfusion in a porcine experimental model. Crit Care 2009; 13.

25. Borges JB, Suarez-Sipmann F, Bohm SH, Tusman G, Melo A, Maripuu E, Sandstrom M, Park M, Costa EL, Hedenstierna G, Amato M. Regional lung perfusion estimated by electrical impedance tomography in a piglet model of lung collapse. J Appl Physiol 2012; 112: 225-36.

26. Hellige NC, Hahn G, Hellige G. Comment on Borges et al. "regional lung perfusion estimated by electrical impedance tomography in a piglet model of lung collapse". J Appl Physiol (1985) 2012; 112: 2127; author reply 28.

27. Bak Z, Sjoberg F, Rousseau A, Steinvall I, Janerot-Sjoberg B. Human cardiovascular dose-response to supplemental oxygen. Acta Physiol (Oxf) 2007; 191: 15-24.

28. Costa EL, Borges JB, Melo A, Suarez-Sipmann F, Toufen C, Jr., Bohm SH, Amato MB. Bedside estimation of recruitable alveolar collapse and hyperdistension by electrical impedance tomography. Intensive Care Med 2009; 35: 1132-7.

29. Costa EL, Lima RG, Amato MB. Electrical impedance tomography. Curr Opin Crit Care 2009; 15: 18-24.

30. Adler A, Amato MB, Arnold JH, Bayford R, Bodenstein M, Bohm SH, Brown BH, Frerichs I, Stenqvist $\mathrm{O}$, Weiler N, Wolf GK. Whither lung EIT: where are we, where do we want to go and what do we need to get there? Physiol Meas 2012; 33: 679-94.

31. Baker GA. Transformation of non-normal frequency distributions into normal distributions. . Annals of Mathematical Statistics 1934; 5: 113-23.

32. Dejours P, Labrousse Y, Raynaud J, Girard F, Teillac A. [Oxygen stimulation of respiration at rest and during muscular exercise at low altitude (50 meters) in man]. Rev Fr Etud Clin Biol 1958; 3: 105-23.

33. Busija DW, Orr JA, Rankin JH, Liang HK, Wagerle LC. Cerebral blood flow during normocapnic hyperoxia in the unanesthetized pony. J Appl Physiol Respir Environ Exerc Physiol 1980; 48: 10-5.

34. Dautrebande L, Haldane JS. The effects of respiration of oxygen on breathing and circulation. J Physiol 1921; 55: 296-9.

35. Gautier H, Bonora M, Gaudy JH. Ventilatory response of the conscious or anesthetized cat to oxygen breathing. Respir Physiol 1986; 65: 181-96.

36. Ferrario D, Grychtol B, Adler A, Sola J, Bohm SH, Bodenstein M. Toward morphological thoracic EIT: major signal sources correspond to respective organ locations in CT. IEEE Trans Biomed Eng 2012; 59: 3000-8.

37. Marquis F, Coulombe N, Costa R, Gagnon H, Guardo R, Skrobik Y. Electrical impedance tomography's correlation to lung volume is not influenced by anthropometric parameters. J Clin Monit Comput 2006; 20: 201-7. 38. Melsom MN, Flatebo T, Nicolaysen G. Hypoxia and hyperoxia both transiently affect distribution of pulmonary perfusion but not ventilation in awake sheep. Acta Physiol Scand 1999; 166: 151-8.

39. Barer GR, Howard P, Shaw JW. Stimulus-response curves for the pulmonary vascular bed to hypoxia and hypercapnia. J Physiol 1970; 211: 139-55.

40. Hambraeus-Jonzon K, Bindslev L, Mellgard AJ, Hedenstierna G. Hypoxic pulmonary vasoconstriction in human lungs. A stimulus-response study. Anesthesiology 1997; 86: 308-15.

41. Grant C, Pham T, Hough J, Riedel T, Stocker C, Schibler A. Measurement of ventilation and cardiac related impedance changes with electrical impedance tomography. Critical Care 2011; 15: R37.

42. Kunst PW, Vonk Noordegraaf A, Hoekstra OS, Postmus PE, de Vries PM. Ventilation and perfusion imaging by electrical impedance tomography: a comparison with radionuclide scanning. Physiol Meas 1998; 19: 481-90.

43. Sjoberg F, Singer M. The medical use of oxygen: a time for critical reappraisal. J Intern Med 2013; 274 : $505-28$.

44. Frerichs I, Hinz J, Herrmann P, Weisser G, Hahn G, Quintel M, Hellige G. Regional lung perfusion as determined by electrical impedance tomography in comparison with electron beam CT imaging. IEEE Trans Med Imaging 2002; 21: 646-52. 